\title{
GESTÃO DO CONHECIMENTO E CAPITAL SOCIAL: AS REDES E SUA IMPORTÂNCIA PARA AS EMPRESAS
}

\author{
Antonio Braz de Oliveira e Silva \\ Marta Araújo Tavares Ferreira
}

\section{Resumo}

O artigo destaca os principais aspectos do conceito de capital social, sua relação com as redes sociais e sua importância para a criação de conhecimento nas empresas. A Análise de Redes Sociais (ARS) estuda as ligações relacionais entre atores sociais. Estes podem ser tanto pessoas, departamentos dentro de uma organização ou empresas de uma região. Os laços entre eles podem ser, por exemplo, amizade, informações sobre produção ou o fornecimento de bens, respectivamente. Parte-se do pressuposto que, nas empresas, as ações dos indivíduos não são autônomas, mas dependem das relações sociais e das rotinas existentes. Por sua vez, a ação das próprias empresas depende de suas redes com outras empresas. Essas redes fazem parte do capital social empresarial, pois mesmo o capital social dos indivíduos pode ser administrado em favor da organização. Observa-se um crescimento da literatura sobre o uso da ARS na pesquisa sobre informação e conhecimento nas empresas.

\section{INTRODUÇÃO*}

A análise de redes sociais (ARS) é uma abordagem oriunda da sociologia, da psicologia social e da antropologia (FREEMAN, 1991). Tal abordagem estuda

O presente artigo é parte da pesquisa doutoral realizada para estudar o cluster da construção em Minas Gerais (SILVA, 2007).
No entanto, a pesquisa em gestão do conhecimento, embora destaque os aspectos relacionados à troca de conhecimento entre indivíduos e ao capital intangível, não utiliza, em geral, o conceito de capital social. A aproximação das análises de gestão do conhecimento com esse conceito seria vantajosa para o avanço da área.

\section{Palavras-Chave}

Capital social, redes sociais, gestão do conhecimento, teoria da firma

as ligações relacionais entre atores sociais. Os atores na ARS, cujas ligações são analisadas, podem ser tanto pessoas, consideradas como unidades individuais, ou unidades sociais coletivas, como, por exemplo, departamentos dentro de uma organização, agências de serviço público em uma cidade, países de um continente 
uma cidade, países de um continente ou do mundo (WASSERMAN; FAUST, 1999).

A rede social é, portanto, um conjunto de pessoas (ou empresas, ou qualquer outra entidade socialmente criada) interligadas (conectadas) por um conjunto de relações sociais tais como amizade, relações de trabalho, trocas comerciais ou de informações.

A idéia de que as relações sociais compõem um tecido que condiciona a ação dos indivíduos nele inseridos é do início do século XX. A metáfora do tecido ou rede, inicialmente usada na sociologia, para associar o comportamento individual à estrutura à qual ele pertence, se transforma em uma metodologia denominada sociometria, cujo instrumento de análise se apresenta na forma de um sociograma (WASSERMAN; FAUST, 1999). Atualmente, observa-se aplicações em muitas outras áreas, como na saúde pública (como se espalham as doenças); tecnologia da informação (a mesma idéia para um vírus de computador); sociologia (os movimentos sociais); economia (mercados e economias de rede) e matemática aplicada (otimização de algoritmos) (WATTS, 1999).

Numa revisão da literatura sobre o paradigma de redes sociais na pesquisa organizacional, Borgatti e Foster (2003) comprovam o crescimento do número de pesquisas que utilizam a metodologia de ARS em várias disciplinas ligadas à admi- nistração e gestão. Esses autores organizaram a revisão classificando as pesquisas nas seguintes categorias: capital social, "embeddedness", e considera que as ações dos indivíduos não são autônomas, mas dependem das relações sociais, rede de organizações e organizações em rede, integração de conselhos, aliança entre empresas e 'joint ventures', gestão do conhecimento, cognição social e uma categoria que agrega todos as demais pesquisas, denominada processos em grupo (group processes).

Na perspectiva da ciência da informação $(\mathrm{Cl})$, as ligações estudadas através da ARS dentro das organizações são capazes de identificar e analisar os fluxos de informação entre os atores, o papel dos diferentes tipos de relacionamento em facilitar esses processos e a ligação das redes informais com aquelas previstas nas normas das empresas.

Assim, os estudos baseados na ARS dentro das empresas foram, em geral, realizados com a intenção de descrever o fluxos de informações e seus efeitos sobre os indivíduos, departamentos (ou outro subconjunto da organização) e na própria empresa. Suas referências são os estudos baseados nas redes de comunicação entre

\footnotetext{
** Algumas das traduções possíveis de embed para o português são: embutir, fixar, ancorar, incrustar, embeber. Assim, embeddedness seria enraizamento ou incrustramento.
} 
atores para a obtenção de informações vantajosas (BORGATTI; CROOS, 2003; BURT, 2001, 1995; GRANOVETTER, 1973). Outras pesquisas envolvem as relações de autoridade formal ou de aconseIhamento técnico em uma organização (ALLEN, 1985; KRACKHARDT, 1987; KRACKHARDT; HANSON, 1993; MOLINA, 2000); a análise de redes de empresas em clusters geograficamente limitados (MACíAS, 2002; SAXENIAN, 1996); o estudo de redes de pequenas e médias empresas (ROCHA, 2003; TOMAÉL, 2005); empreendedorismo e redes familiares (LIN et al. 2001) e as redes entre grandes empresas e seus fornecedores (CARLEIAL, 2001).

Existe uma discussão epistemológica em torno da análise de redes sociais. Para muitos autores, trata-se de uma metodologia de análise de dados relacionais que permite a captação de diversos fenômenos sociais que se deseja estudar segundo uma área de conhecimento específica; já para alguns, trata-se de um novo paradigma de análise estrutural (DEGENNE; FORSÉ, 1994). Para outros, é uma tentativa de se introduzir um nível intermediário entre os enfoques micro e macro na análise da realidade social, ou entre o indivíduo e a estrutura, nas principais correntes da sociologia (MARTELETO, 2001). De qualquer forma, há uma linguagem comum e métodos de coleta e análise de dados que podem ser utilizados em vários modelos teóricos, o que, por si só, representa uma imensa vantagens para os estudos organizacionais.

\section{REDES E CAPITAL SOCIAL}

O interesse pelos estudos sobre redes sociais está relacionado, também, com o aumento dos estudos na área de economia e sociologia sobre a importância do capital social. De acordo com Burt (2000) o conceito de capital social está se tornando relevante para as áreas de administração, sociologia e economia. O capital social é multidimensional, o que significa que ele é capaz de incorporar vários níveis e unidades de análise. Assim, os estudos e pesquisas usam combinações de diferentes metodologias de pesquisa quantitativa e qualitativa para sua mensuração.

A literatura econômica reconhece diferentes formas de capital, que em comum têm a possibilidade de serem acumulados. Muitas formas de capital possuem, também, características que permitem que sejam valoradas e transacionadas no mercado, ou seja, o mercado determina o seu preço e a sua disponibilidade. O capital social é uma forma de capital nãomercantil. Embora sua definição seja alvo de discussão na ciência econômica e na sociologia, algumas características parecem se destacar, como a não ocorrência de retornos decrescentes, a apreciação com o uso (não se deprecia, portanto), a 
produção coletiva a partir das relações sociais existentes nas comunidades, mas seus benefícios não podem ser antecipadamente mensurados. Embora possua características de bem público, observa-se nele um aspecto único, ou seja, a sua produção é, necessariamente, coletiva.

O capital social gera externalidades, mas sua análise deve transcender esse ponto, isto é, o capital social deve ser entendido como um conjunto de redes e normas que permitem a redução dos riscos decorrentes das relações entre desconhecidos e, conseqüentemente, dos custos de transação. No entanto, sua mensuração é bastante problemática e embora ele possa ser associado ao desenvolvimento, especialmente local, sua promoção não é trivial, ou seja, como ele está incrustado nas redes de relações sociais, não é claro como a sua expansão ou modificação pode afetar o bem-estar de seus componentes.

Segundo Burt (2000), a maioria dos trabalhos o apresenta como uma metáfora da vantagem (BOURDIEU, 1985; BURT, 1995; COLEMAN, 1990; PUTNAM, 1996), o que já era esperado devido ao estágio de difusão inicial do conceito. As vantagens que os indivíduos teriam seriam fruto de suas habilidades individuais (capital humano) num contexto definido pelo capital social, em termos de melhores conexões com outros indivíduos, sendo que estas compo- riam uma parcela dos ativos do capital social.

A maior parte dos estudos sobre 0 capital social destaca as contribuições de três teóricos (DURSTON, 2002): I) James Coleman, para quem o capital social é um recurso para o indivíduo que pertence a uma determinada estrutura, tratando-se de um recurso coletivo; ii) Robert Putnam que, de forma semelhante, trata o capital social como um recurso coletivo baseado nas normas e redes de intercâmbio entre os indivíduos; e iii) Bourdieu (1985), que trata o capital social como a soma dos recursos decorrentes da existência de uma rede de relações de reconhecimento mútuo institucionalizada. Os recursos são empregados pelas pessoas em uma estratégia de progresso dentro da hierarquia social, prática resultante da interação entre $o$ indivíduo e a estrutura.

Vários problemas de pesquisa são enfrentados, de maneira adequada, com o uso do conceito de capital social, mas podem ser aprofundados com mais eficiência se os mecanismos de rede forem melhor entendidos (BURT, 2000). A pesquisa sobre o capital social, em seu núcleo, apresenta uma metodologia - a análise de redes sociais - e um problema de pesquisa fundamental relacionado ao desempenho, qual seja, de permitir identificar, com o uso de modelos rigorosos, a razão pela qual certas pessoas e organizações têm de- 
sempenho melhor do que as demais. Assim, o autor tenta definir as estruturas de rede que determinam o capital social, que seriam baseadas no tipo de conexões existentes entre os atores.

No entanto, conforme se observa na fig.1, não há acordo em definir o que seriam as 'melhores conexões'. Nessa figura estão representadas as linhas de discussão dos mecanismos que definem a criação do capital social, mas as duas linhas apresentadas à direita (fechamento e intermediação) são as que permitem operacionalização e mensurações mais adequadas (BURT, 2000).
Os dois mecanismos assumem que a comunicação demanda tempo e que ela vai circular mais rapidamente dentro dos grupos menores do que entre grupos distintos.

Como resultado, as pessoas não estão informadas de todas as oportunidades existentes em todos os grupos e como sua difusão demanda tempo, alguns indivíduos possuem vantagens por serem informados antes dos demais. Nesse ponto, os dois mecanismos passam a ser distintos.

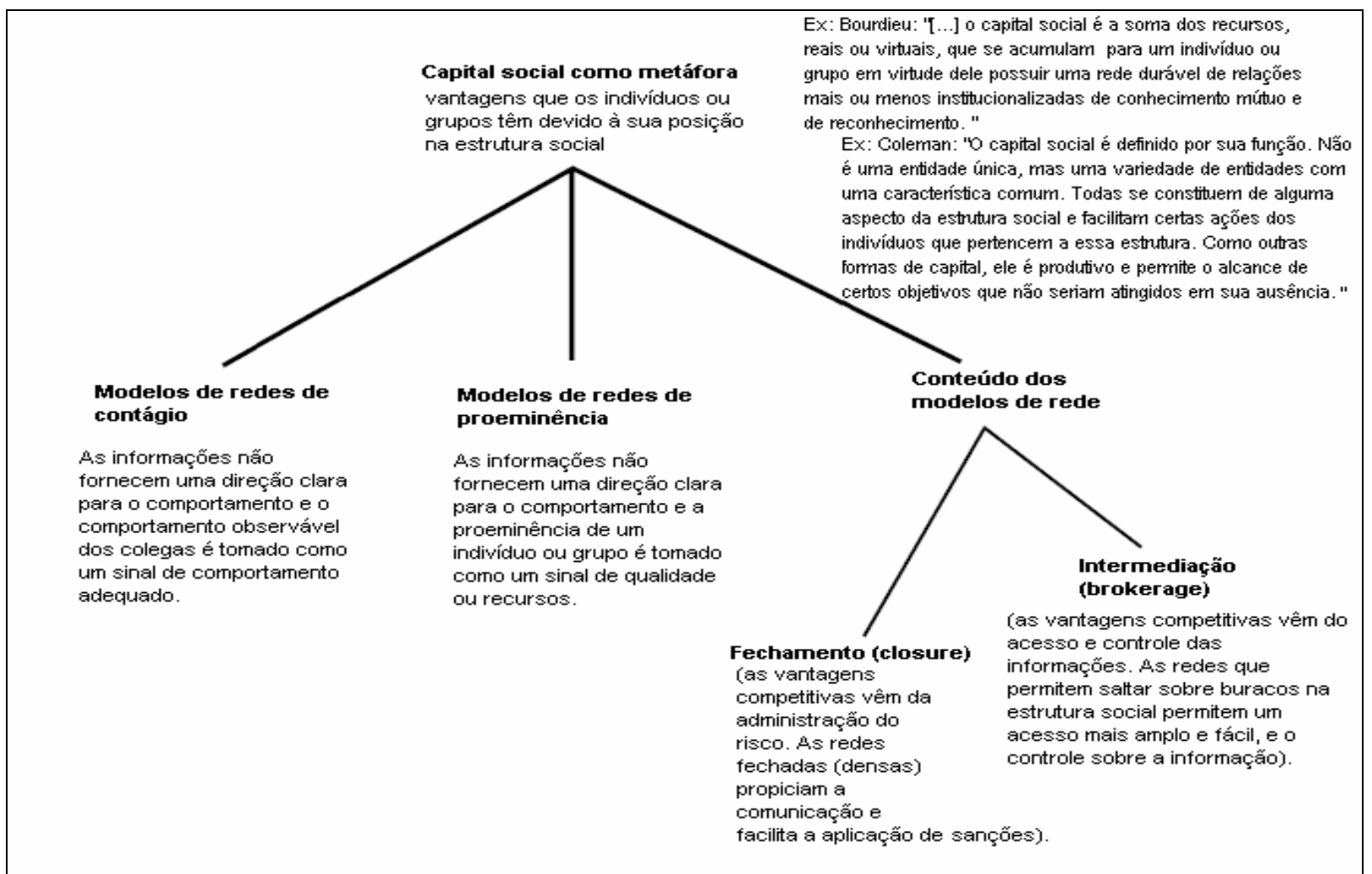

FIGURA 1 - Capital social como metáfora e estrutura de rede Fonte: Adaptado de Burt (2000)

No caso do fechamento, as relações dentro dos grupos são mais importantes e todos estão conectados (rede densa), diminuindo-se o custo de processamento da informação e o risco dela ser incompleta, uma vez que, pelo fato da 
rede ser densa, há maiores possibilidades de se aplicar sanções aos indivíduos que têm um comportamento oportunista (COLEMAN, 1990 apud BURT, 2000).

Já no outro mecanismo, de intermediação, a capacidade de obtenção de novas informações é a forma pela qual se manifesta o capital social, e os indivíduos que são intermediários entre diferentes grupos (brokers) possuem maior capital social. A criatividade e o aprendizado são fundamentais para o surgimento de novas idéias, mas são os contatos com diferentes grupos que permitem aos intermediários a obtenção de informações novas. Porém, não se trata apenas do intermediário ser um canal de informações, mas, também, de ser capaz de gerar novos conhecimentos, isto é, analisar a qualidade da informação com respeito às necessidades do grupo. Assim, outros fatores influenciam na eficácia dos intermediários, especialmente o seu capital humano.

Em pesquisa realizada para identificar a importância dos dois mecanismos, Burt (2000) analisou várias características das redes pesquisadas (tipos de relação, densidade, tamanho, existência de buracos estruturais, dentre outras). Enquanto o mecanismo de fechamento está associado à confiança, o de intermediação se relaciona com a mudança. Este permite a obtenção de novos recursos e a geração de valor, enquanto o primeiro viabiliza a realização do valor criado. Essa conjugação dos dois mecanismos é um elemento importante para a compreensão e o avanço no uso do conceito de capital social (BURT, 2000, 2001). Sua importância é evidente no estudo das redes internas das organizações e das redes entre organizações em um cluster.

O capital social não deve ser confundido com o capital humano nem com infra-estrutura. $O$ capital humano engloba as habilidades e conhecimentos dos indivíduos que, em conjunto com outras características pessoais. Parte desse capital está associada ao processo, formal ou informal, de aprendizagem pelo qual todos passam, mas tanto a sua aquisição quanto o seu uso são processos afetos ao indivíduo. A infra-estrutura se refere ao conjunto fundamental de instalações e meios para que a produção se realize e se distribua. O capital humano é condição necessária, mas, freqüentemente, não é suficiente para que o indivíduo tenha acesso amplo às informações ou outros recursos, que podem ser alcançados a partir de suas redes de relações.

Dito de outra forma, entre indivíduos com o mesmo capital humano, têm melhores oportunidades aqueles com maior capacidade de utilizar o seu capital social (DEGENNE; FORSÉ, 1994). 
Muitas críticas foram feitas ao conceito de capital social, assim como à sua utilização indiscriminada, como se fosse uma panacéia para remediar todos os males da exclusão social e como se permitisse resolver os problemas do baixo nível de desenvolvimento. Esse risco do conceito de capital social ser usado de forma simplista como sinônimo de tudo que se refere aos aspectos sociais da vida, apontado, dentre outros, por Lin et al. (2001), aumenta a necessidade de se ampliarem os programas de pesquisa que permitam $o$ delineamento dos padrões de distribuição dos recursos sociais e sua influência sobre o indivíduo, a demonstração robusta de que se trata de capital, isto é, que gera retorno sobre os investimentos realizados para a sua obtenção e a demonstração de causalidade entre os recursos incrustados e os limites da ação individual.

De acordo com Glaeser, Laibson e Sacerdote (2002) as bases teóricas para a mensuração empírica dos impactos do capital social são bastante claras, mas o mesmo não acontece com a identificação dos mecanismos associados à criação do capital social. Parte da dificuldade é atribuída ao fato de que o verdadeiro proprietário do capital social não é o indivíduo, mas a comunidade, através da rede de relações existentes. Assim, os economistas, por exemplo, têm dificuldade em criar um quadro conceitual no qual a comunidade funcionaria como uma unidade capaz de tomar decisões autônomas.

Por outro lado, se é verdade que as redes sociais dificultam o surgimento da figura do carona (free rider, aquele individuo que se beneficia sem contribuir), dificultando o oportunismo, podem, também, funcionar no sentido inverso, para excluir novos participantes, impor normas que prejudiquem grupos específicos dentro de uma comunidade (como por exemplo, mulheres, praticantes de determinada religião, etc.) ou atitudes com relação a outros grupos, como para impedir que outras comunidades tenham acesso a determinados serviços públicos.

Portanto, é importante destacar que nem toda forma de capital social é positiva e que ele pode ser usado negativamente contra aqueles que estão fora de uma determinada rede, ou pode, ainda, gerar grupos corruptos e sistemas autoritários. O capital social pode funcionar, também, como um inibidor das iniciativas individuais, além de impor restrições à liberdade, dependendo das normas e sanções originadas a partir das relações culturais na comunidade. 
3 O CAPITAL SOCIAL E O ACESSO À INFORMAÇÃO DENTRO DAS ORGANIZAÇÕES

Muitas pesquisas nas ciências sociais que utilizam os conceitos e a metodologia de análise de redes sociais tentam identificar a organização de grupos específicos dentro de comunidades maiores, a partir de problemas específicos associados ao acesso a recursos. Conforme já exposto, os fluxos de informação e conhecimento que circulam pelos laços existentes entre os membros da comunidade dependem de características culturais e políticas que regulam, também, a participação de cada um no acesso aos benefícios e as sanções para aqueles que não colaboram ou participam. A posição de cada indivíduo na rede depende do quanto ele agrega ao capital social do conjunto e a margem de decisão de cada um está sujeita à distribuição de poder, à estrutura de interdependência e às tensões no interior do grupo, de forma que as estruturas representadas nas redes determinam, em grande parte, a atuação dos indivíduos.

Em outras palavras, o capital social está associado à localização dos atores na rede e aos recursos sociais nela incrustados, numa associação positiva, pois uma melhor localização aumenta a possibilidade de se mobilizar os melhores recursos. O estudo, nas organizações, dos fluxos de informação com base nas redes sociais implica em analisar as relações de poder existentes, com todas as dificuldades inerentes ao seu conceito. Os conceitos de buraco estrutural e de intermediários (brokers) ou atores capazes de 'saltar' sobre eles (BURT,1995), criando pontes entre diferentes grupos, podem ser aplicados. Os intermediários têm vantagens sobre os demais atores por construírem uma rede de informações que garante o acesso às oportunidades existentes, de três formas: I) controle sobre o acesso e o conhecimento de quem melhor pode usar a informação; ii) uso privilegiado e antecipado em relação aos demais, e iii) ampliação de sua legitimação.

As relações de confiança existentes na rede são fundamentais para o papel do intermediário, uma vez que, dada a capacidade limitada de processamento de informação por parte dos indivíduos (racionalidade limitada), a qualidade da informação recebida não pode ser integralmente verificada e, assim, sua qualidade depende da reputação das fontes. Além da confiança, os intermediários devem ser capazes de identificar quem pode fazer melhor uso da informação disponível, sem o que não poderiam tirar vantagem de sua posição (BURT, 1995, 2000, 2001). 
Segundo Borgatti e Foster (2003), dentre os estudos sobre organizações que utilizam a ARS, a maior parte envolve o conceito de capital social. Além dos trabalhos de Burt (1995, 2001), muitos outros são citados em Borgatti e Foster (2003), envolvendo poder, liderança, mobilidade, acesso a emprego, desempenho e criatividade individuais, e empreendedorismo.

$\mathrm{Na}$ área sob a denominação de gestão de conhecimento, a aplicação do conceito de capital social para explicar o comportamento informacional dos gerentes é utilizada, assim como nos estudos relacionados às condições internas às empresas para que haja a criação de novos conhecimentos, por autores que analisam o funcionamento das redes internas sem, no entanto, utilizar a ARS, como Brown e Duguid (2001) e Davenport e Prusak (1998).

Outros autores entendem que ainda há uma carência de estudos sobre as redes existentes nas organizações. Grosser (1991) analisa sua a importância para a troca de informação entre pessoas e, segundo ele, "[...] existe pouco reconhecimento de que as pessoas podem constituir o mais importante recurso de informação em qualquer organização" (GROSSER, 1991, p.351, tradução nossa). Ele destaca a contribuição de Mintzberg (1979), outro autor que mesmo não utilizando a metodologia de ARS, dedica especial atenção aos fluxos de informações na organização e também a sua estrutura informal.

Um dos trabalhos mais importantes sobre redes internas de empregados existentes dentro das empresas é o de Krackhardt (1987). Numa empresa fabricante de bens de capital de alta tecnologia, os 21 gerentes foram consultados, primeiramente, sobre as suas próprias redes envolvendo vários tipos de relacionamento, tais como os de amizade e os de aconselhamento técnico. Em seguida, eles foram consultados sobre a sua percepção das redes de aconselhamento técnico dos demais gerentes. Finalmente, os resultados obtidos nessas duas etapas foram comparados com a rede formal definida pelo organograma da empresa. A rede obtida da percepção de cada um sobre as redes dos demais 20 gerentes foi comparada com a rede efetiva construída para o conjunto a partir das respostas obtidas das consultas da primeira fase. Os resultados mostraram que alguns gerentes tinham uma percepção errônea de sua importância e que aqueles com posição mais alta na hierarquia tinham melhor percepção de suas redes e das dos demais. Em outro trabalho, com o objetivo mais específico de identificar as redes informais por trás do organograma da empresa, Krackhardt e Han- 
son (1993) buscaram identificar as diferentes redes nas quais os indivíduos estavam envolvidos em uma empresa, mostrando que diferentes relações podem ser estudadas em uma organização, por meio da metodologia de ARS e os seus resultados podem servir como suporte aos trabalhos dos seus gerentes e executivos.

Em uma ampla pesquisa sobre 0 comportamento informacional dos engenheiros em laboratórios de pesquisa e desenvolvimento (P\&D), Allen (1985) mostra a importância da superposição de diferentes laços nas redes para que a busca por informações tecnológicas e aconselhamento apresente maior eficácia. Para chegar a essa conclusão, ele pesquisou, inicialmente, o comportamento informacional dos engenheiros e suas preferências pelos vários tipos de fontes de informação. Uma vez constatada a importância das fontes pessoais, elas foram analisadas separando-se, inicialmente, as fontes internas e externas.

Em seguida, as posições dos engenheiros nas duas redes foram confrontadas de forma a se identificar algumas características relevantes para o aprimoramento dos sistemas de informação existentes de P\&D. O autor conclui que os engenheiros que são mais procurados por outros dentro dos projetos de pesquisa se caracterizam por terem ele- vado reconhecimento por sua competência técnica.

Outra conseqüência dessa capacidade é sua promoção para postos de coordenação de equipes. Por outro lado, são, também, aqueles com melhores contatos fora de seu próprio departamento e da própria empresa. Assim, eles funcionam como gatekeepers, trazendo informações relevantes e não redundantes para dentro da empresa. $O$ autor destaca que, inicialmente, a discussão em torno das novas informações é feita dentro de grupos menores, compostos por outros gatekeepers ou apenas pela equipe do projeto, antes de serem disseminadas mais amplamente (ALLEN, 1985).

Essa conclusão valida o esforço de Burt $(2000,2001)$ de conciliação dos mecanismos que definem o capital social: intermediação (o engenheiro gatekeeper tem acesso a informações fora de seu grupo) e fechamento (o engenheiro gatekeeper dissemina a informação, em primeiro lugar, entre os membros de um grupo menor, mais coeso e mais fechado, com os quais tem laços mais fortes).

Esses aspectos são relevantes para a compreensão da importância do capital social no interior das organizações. Um possível modelo, seria, conforme, Borgatti e Cross (2003),

baseado numa revisão da literatura de redes sociais, processa- 
mento da informação e aprendizagem organizacional, [...] um modelo formal de busca de informação no qual a probabilidade de buscar informação junto a outra pessoa é função: 1) do conhecimento sobre o que a outra pessoa sabe; 2) do valor atribuído a esse conhecimento; 3) do ganho de tempo estimado em se obter acesso a esse conhecimento; 4) do baixo custo associado a essa forma de busca de informação. Adicionalmente é feita a hipótese que as variáveis 'conhecimento', 'acesso' e 'custos' determinam a relação entre proximidade e busca por informação (BORGATTI; CROSS, 2003, p.440, tradução nossa).

$\mathrm{Na}$ análise feita por Molina (2000), que se baseia nas conclusões de Mintzberg (1979), o organograma de uma empresa representa um arranjo institucional racional e consciente da divisão do trabaIho, segundo uma tradição weberiana de análise das organizações burocráticas. A sua estruturação em divisões funcionais que não se superpõem, e nas quais a hierarquia e as normas de procedimento garantem um funcionamento formal e impessoal entre seus membros, se transformou num padrão administrativo mundial (MOLINA, 2000).

Os vários níveis dentro de uma organização representam uma divisão de trabalho ditada pela especialização e a sua coordenação fica sob a responsabilidade dos níveis hierárquicos mais elevados, com o objetivo de conseguir níveis adequados de produtividade. Essa estru- tura, teoricamente, diminui os custos de obtenção de informações.

As novas tecnologias de informação e comunicação (TIC's) e as novas metodologias de administração (qualidade total, just-in-time e organizações em rede) afetam significativamente a organização das empresas em direção a estruturas mais flexíveis e incentivam a criação de redes de empresas (entre clientes, fornecedores, etc.) ou, ainda, a sua estruturação em torno de projetos ou no formato misto (matricial) (MOLINA, 2000).

De qualquer forma, a empresa busca se adaptar às novas situações e adequar suas estruturas, de forma que elas minimizem os custos de obtenção de informação. As pessoas participam da rede formal, conforme definida pelo organograma, mas fazem parte, também, de outras redes informais. Como assinalado no trabalho de Allen (1985), há uma superposição entres as redes, e, segundo Molina (2000), essa característica é relevante para o bom funcionamento da empresa. Além disso, se a empresa participa de um mercado dinâmico, os organogramas tendem a mudar mais lentamente do que as redes informais.

Dessa forma, acompanhar as redes informais internas passa a ser um elemento relevante para os gerentes e executivos. Essa conclusão reforça a observação de Allen (1985) e impõe novos de- 
safios para a definição dos sistemas internos de informação.

A divisão social do trabalho leva à especialização de pessoas e organizações, que passam a se dedicar às suas próprias atividades e tarefas, excluindo outras, mesmo adjacentes. Dessa forma, surgem buracos na estrutura da organização social da produção e os grupos funcionais internos deixam de acompanhar outras funções e os ambientes externos. Com isso, os benefícios advindos da troca entre as pessoas passam a ser mal avaliados porque elas deixam de saber o que podem oferecer para trocar, desconhecendo "as múltiplas taxas de retorno das relações de troca"1, conforme Burt, Hogarth e Michaud (2000, p.3).

Por outro lado, os indivíduos conectados com outros grupos enxergam a importância da função de coordenação dos trabalhos realizados pelos diferentes grupos e do conhecimento das informações de que eles necessitam. Esses indivíduos são ricos em capital social, que está associado à sua capacidade de construir pontes sobre os buracos estruturais (devido à inexistência de conexões entre os grupos). Eles são denominados 'gerentes empreendedores', atuando em canais mais flexíveis e rápidos do que os caminhos burocráticos e, portanto, são mais eficientes ao atingir mais pessoas em diferentes grupos. Eles são, também, melhor avaliados e recebem promoções relativamente mais rápido que os demais, assim como remunerações mais elevadas (BURT; HOGARTH; MICHAUD, 2000).

Para identificar se essas características dos gerentes e os benefícios associados são generalizáveis ou se estão relacionadas a um conjunto de instituições e à cultura de um de-terminado país, esses autores com-pararam empresas nos EUA e na França. Esses paises, segundo os autores, pos-suem culturas empresariais significa-tivamente distintas entre si (BURT; HOGARTH; MICHAUD, 2000). Os resultados mostram semelhanças entre o comportamento dos gerentes e as suas recompensas nas duas economias, isto é, os gerentes com redes mais amplas, ainda que menos densas e controladas, recebem melhores salários e promoções mais rápidas. Dessa forma, os autores concluíram que há uma relação positiva entre o capital social dos gerentes, medido por sua capacidade de 'saltar' os buracos estruturais nas redes de informação, e seu desempenho, este medido pelo acesso a uma maior remuneração e menor tempo decorrido entre suas promoções (BURT; HOGARTH; MICHAUD, 2000). Os gerentes de ambas as nacionalidades possuíam redes com o mesmo formato e topologia, assim como

${ }^{1}$ Multiple rates of return to exchange relation. Inf.Inf., Londrina, v. 12, n. esp., 2007. 
os mapas cognitivos de suas redes eram similares, e apontaram para uma característica que pode ser universal nas empresas, a saber, a eficiência dos gerentes associada à sua capacidade de saltar os buracos estruturais na obtenção de informações relevantes (brokerage) (BURT; HOGARTH; MICHAUD, 2000).

Concluindo essa seção, segundo Degenne e Forsé (1994), o uso da metodologia de análise de redes sociais é a abordagem mais adequada para a mensuração do capital social, pelo menos no nível micro (no interior das firmas) e meso (entre as firmas).

\section{A FIRMA E A GESTÃO DO CONHE- CIMENTO}

O objetivo desta seção é analisar a firma ${ }^{2}$, destacando o seu papel como unidade que processa informações e produz conhecimentos. Essa apresentação é importante uma vez que a literatura sobre Gestão do Conhecimento não discute a teoria da firma. Para cumprir suas funções, as firmas se organizam em estruturas que visam diminuir os custos de obter e trocar informações. São, também, or-

\footnotetext{
${ }^{2}$ Muitas vezes, os termos 'firma' e 'organização' e, em menor grau, 'empresa', são usados, em várias ocasiões, como sinônimos. As firmas são organizações com uma hierarquia, divisão do trabalho e uma estrutura de gerência executiva que planeja e decide sobre as questões que afetam o seu desenvolvimento (KERSTENETZKY, 1995). Essa mesma forma de emprego dos termos como substitutos pode ser observada, por exemplo, em Williamson (1995).
}

ganizações sociais e os indivíduos que as compõem são os responsáveis por esses processos. Os indivíduos participam de várias redes sociais, algumas contidas no interior das empresas, outras com pontos de interseção com indivíduos de outras firmas, como as redes de relações profissionais. Essas redes são vistas como canais que facilitam os fluxos de informações.

Existem diferentes conceitos de firma na teoria econômica e na administração, e muitas abordagens destacam as suas competências, a criação de conhecimentos e a capacidade de inovação. As iniciativas gerenciais que visam facilitar o aprendizado e a inovação podem ser analisadas com as ferramentas agrupadas sob um grande guarda-chuva denominado 'gestão do conhecimento'. Essas técnicas de gestão valorizam os aspectos sociais da organização, sem perder de vista a tecnologia. Além disso, permitem a administração do capital social das empresas, composto, em grande medida, pelas redes sociais de seus empregados. Ainda assim, na literatura de referência mais usada no Brasil sobre Gestão do Conhecimento, pouco se utiliza a análise de redes sociais (ARS).

Ronald Coase, ao tratar das instituições em sua aula magna que ocorreu durante a cerimônia de entrega do Prêmio Nobel de Economia, destacou que os 
economistas tratam as firmas como 'caixas-pretas', por não se interessarem pela sua estrutura interna de funcionamento, mas apenas pelos mercados, pelas compras dos fatores de produção e pela venda dos bens produzidos com o uso desses fatores:

isso é extraordinário uma vez que a maior parte dos recursos em um sistema econômico moderno são empregados pelas firmas, e como esses recursos são usados depende de decisões administrativas e não, diretamente, das operações de um mercado. Conseqüentemente, a eficiência do sistema econômico depende, de uma maneira bastante considerável, de como essa organização conduz os seus negócios, em particular as grandes empresas modernas (COASE, 1991, [s.p.]).

Numa economia capitalista moderna, a maior parte da produção de riquezas é feita pelas empresas. A teoria que se ocupa da produção, na literatura econômica, é denominada 'teoria da firma', embora englobe abordagens teóricas bastante diferentes, uma vez que não se produziu uma definição clara e amplamente aceita da firma (KERSTENETZKY, 1995).

$\mathrm{Na}$ teoria neoclássica, a firma é tratada de uma forma mais ou menos abstrata e seria, apenas, o local que reúne fatores de produção (capital e trabalho) que se combinam de acordo com a tecnologia disponível e de conhecimento comum, comportando-se, assim, como um ator passivo, que toma a tecnologia, os preços dos fatores e a capacidade organizacional como dados. Aspectos organizacionais ou de relacionamento com clientes e fornecedores são ignorados. A natureza da firma com respeito às suas decisões de produção e de investimento, bem como aspectos de organização interna, tais como a estrutura hierárquica e os processos de controle, por exemplo, são irrelevantes e, portanto, ignorados (FEIJÓ; VALENTE, 2004).

Nessa teoria, o sistema de preços da economia funcionaria como um sistema de informações totalmente adequado a um regime no qual as firmas e os consumidores têm amplo conhecimento das variáveis relevantes para processar suas escolhas.

Mudanças ocorridas na teoria da firma usada na economia buscaram introduzir aspectos de comportamento mais próximos daqueles verificados na realidade, destacando-se os processos de tomada de decisão e incorporando outros objetivos, além da maximização do lucro, nos procedimentos de análise.

Nessas abordagens, as firmas são descritas a partir de suas atribuições básicas de produção e das rotinas a ela associadas. Suas relações com outras firmas são reguladas por contratos, o que levou ao questionamento, por parte de alguns economistas, dos mecanismos de 
mercado e dos sistemas de preços como suficientes para coordenar a produção de bens e serviços.

Esse questionamento tomou a forma de uma questão simples, qual seja, por que as firmas existem, e foi a resposta a essa pergunta que, justamente, levou Ronald Coase ao reconhecimento pela Academia Real de Ciências da Suécia. Segundo Granovetter (1994), ao se fazer essa simples e inócua questão, que pode ter ocorrido a outros, mas não havia sido objeto de uma investigação sistemática, Coase iniciou uma revolução silenciosa:

Em sua resposta, agora famosa, e grandemente elaborada por $\mathrm{O}$ liver Williamson numa série de trabalhos que divulgaram o seu programa de pesquisas sobre mercados e hierarquias, as firmas existem em função da presença de custos de transação e pelo sistema de preços não pode prover toda a informação necessária requerida pelos pequenos produtores isolados em cada transação que necessitem realizar no mercado (GRANOVETTER, 1994, p.453, tradução nossa).

Em outras palavras, existem custos associados ao uso dos mecanismos de preços, tais como obter informações, escrever e controlar contratos, acompanhar as transações no mercado, etc. Assim, como alternativa ao sistema de preços como mecanismo de coordenação, a firma se coloca como uma instituição hie- rárquica, na qual a alocação de recursos é resultado de decisões administrativas:

os empresários, ao decidir sobre a condução dos negócios e sobre o que produzir, levam em conta os custos de transação. Se os custos superam os ganhos [...] não haverá produção. Dessa forma, os custos de transação afetam não apenas os arranjos contratuais, mas também quais bens e serviços serão produzidos (COASE, 1991, [s.p.], tradução nossa).

Dessa forma, Coase (1937) traz uma nova abordagem sobre a firma que possibilita o surgimento de um programa de pesquisa distinto do programa neoclássico. De maneira simplificada, os custos de se obter informações e controlar os contratos são minimizados no interior das firmas.

As escolhas entre produzir internamente ou comprar no mercado seriam feitas no interior de uma estrutura hierárquica, com os gerentes respondendo às forças do mercado e balanceando constantemente o custo de usar o mercado com o custo da organização interna. Os limites da firma passam a ser dados pela escolha entre quais atividades devem ou não ser realizadas internamente, ou seja, entre 'fazer ou comprar' (FElJÓ; VALENTE, 2004; KERSTENETZKY, 1995).

De acordo com Pavitt (2001), Edith Penrose foi um dos poucos eminentes 
economistas do século XX a considerar que aquilo que acontece dentro das firmas é importante para a economia, desenvolvendo uma abordagem inovadora e extremamente importante sobre o tema (PAVITT, 2001). Para Kerstenetzky (1995, p.120), o trabalho de Penrose pode ser visto como "a base sobre a qual se assenta boa parte dos esforços contemporâneos de constituição de um paradigma alternativo para a teoria da firma".

Segundo Penrose (1959), a firma só pode ser definida em função do que ela faz ou do que é feito nela, mas cada analista pode escolher uma ou mais características e definir a firma segundo seus interesses de pesquisa. Para a autora, a função econômica básica da firma é fornecer os bens e serviços demandados, com a utilização de recursos produtivos de acordo com os planos desenvolvidos em seu interior. Portanto, a firma planeja, e suas diferentes atividades internas e os departamentos são coordenados pela existência de uma política desenhada ao se pensar a firma como um todo, isto é, segundo a estratégia definida para o negócio (PENROSE, 1959).

Penrose (1959) considera útil o conceito de rotinas organizacionais e reconhece que muito do conhecimento fundamental para a diversificação e crescimento da firma existe em sua forma tácita e é aprendido pela experiência. En- quanto o conhecimento gerado internamente na empresa for importante para a sua competitividade, ele irá crescer, mas, como conseqüência, as empresas serão cada vez menos auto-suficientes, mais dependentes de fontes externas de conhecimento e passarão por mais dificuldades para se organizarem internamente.

Penrose foi a primeira autora a conceber uma análise da firma centrada em suas capacidades (organizational capabilities), ou seja, a firma é tanto uma organização administrativa quanto uma coleção de recursos produtivos. Em sua análise, a autora distingue recursos e serviços dos recursos. Recursos podem ser definidos independentemente do seu uso, enquanto os serviços providos pelos recursos não podem.

Portanto, inputs não são simplesmente fatores de produção. Eles são serviços de fatores para a firma, de forma que as características produtivas destes serviços são determinadas pelo contexto organizacional no qual são usados, isto é, eles são específicos para cada firma (FEIJÓ; VALENTE, 2004).

A firma é uma organização e os recursos que ela administra, inclusive os gerenciais, são os fatores que impulsionam o seu crescimento, mas este é limitado pelo tempo e pela capacidade de se adquirir novos conhecimentos. Os recursos gerenciais são específicos e neles 
estão depositados os conhecimentos e a experiência da firma (KERSTENETZKY, 1995). Penrose (1959) introduz o conceito de equipe de trabalho (teamwork), destacando a importância do conhecimento tácito, da confiança e das redes (PENROSE, 1959).

Para se reduzir a incerteza sobre 0 desenrolar futuro dos acontecimentos é preciso obter mais informações sobre os fatos relevantes, e uma das tarefas mais importantes da firma, num mundo de incertezas, é obter o maior volume possível dessas informações. Para obtê-las, são necessários maiores recursos, enquanto que para interpretá-las, são necessários 'serviços gerenciais' ('services of existing managemet'). A combinação dos recursos com a capacidade de interpretação foi denominada, pela autora, de 'pesquisa gerencial' ('managerial research) (PENROSE, 1959).

A concepção da firma de Penrose adianta uma série de atributos que, atualmente, são amplamente destacados na literatura sobre gestão. Sem ordem de importância, pode-se mencionar, em primeiro lugar, a necessidade de se pensar que a firma pressupõe $o$ trabalho em equipe (teamwork), que demanda tempo para ser constituída e para ser, progressivamente, incrementada. Em segundo lugar, o crescimento da firma está associado à acumulação de conhecimento em seu interior, ou em outras palavras, sob controle de suas equipes.

Sendo assim, destaca-se um terceiro elemento associado ao conhecimento tácito dos membros da equipe e ao aprendizado organizacional. Segundo essa autora, o conceito de conhecimento experimental é central, pois ela argumenta que todo gerente tem qualificações práticas e conhecimentos técnicos que não são facilmente codificados. A teoria da firma de Penrose é, portanto, uma 'teoria da firma que aprende' (learning theory of the firm), visto que, na sua concepção, não só produtos e serviços são produzidos, mas também conhecimentos (FEIJÓ; VALENTE, 2004).

No interior de cada firma, cada indivíduo tem apenas uma parcela do conhecimento a ser utilizado na solução de um problema, mas a equipe detém o conhecimento completo necessário para a tarefa. O aprendizado resultante da solução do problema afeta as competências individuais de maneira dependente da composição da equipe, ou seja, da divisão interna do trabalho e dos processos internos à equipe. As competências organizacionais seriam o resultado desses processos internos, combinadas com a aprendizagem decorrente da divisão do trabalho entre firmas, isto é, das redes nas quais cada uma está envolvida (RICHARDSON, 1972). 
A teoria evolucionária da firma, que tem no trabalho de Nelson e Winter (1982) um marco, busca analisar as respostas das firmas e da indústria às mudanças no seu ambiente, em função de alterações no seu próprio mercado, do crescimento econômico e da introdução de inovações. Segundo os autores, as firmas são tratadas a partir de suas capacidades e seu comportamento anterior, mas o conjunto de regras de decisão, tomado como referência na análise, não pertence à teoria econômica neoclássica (NELSON; WINTER, 1982). Na verdade, essas regras são os padrões de comportamento normais e previsíveis ou, em outras palavras, 'rotinas'.

Ao destacarem o papel das rotinas, os autores reconhecem que elas apontam para um possível comportamento (ou, ao menos, indicam a capacidade de se adotar esse comportamento), mas não de forma determinista, uma vez que existem as influências do ambiente. As rotinas podem ser transmitidas, indicando que o comportamento de amanhã é determinado pelas rotinas correntes e que elas podem ser usadas na reprodução dos processos em uma outra planta industrial, por exemplo.

As firmas e suas rotinas são, também, alvo de seleção, já que umas executam melhor que outras as suas funções (NELSON; WINTER, 1982). Não se trata de considerar que todas as tarefas de decisão sejam rotineiras. Os processos de tomada de decisão da alta administração estão longe de serem rotineiros, mas - que é regular e previsível pode ser classificado sob essa denominação.

A firma usa as mesmas rotinas até que se tenha algum motivo para alterálas. Elas podem, por exemplo, fornecer resultados insatisfatórios. Nesse caso, uma outra área da empresa pode possuir rotinas para identificar essas anomalias. Alternativamente, a firma pode, de tempos em tempos, se engajar na análise de suas rotinas com a intenção de melhoria, revisão ou mesmo alteração radical.

Nesse caso, normalmente se recorre à figura de um consultor externo, já que as rotinas existentes estão incrustadas (embedded) nos empregados, o que dificulta sua avaliação pelos envolvidos diretamente na execução (NELSON; WINTER, 1982).

As rotinas da firma são, em grande medida, parte do conhecimento tácito de seus membros, "não sendo transferível por meios formais e compondo o caráter idiossincrático da atividade empresarial" (KERSTENETZKY, 1995, p.61). O conhecimento das rotinas é fundamental para o funcionamento da firma, pois uma grande parte do conhecimento para o desempenho do negócio não se encontra registrado em manuais, documentos ou, 
ainda, no desempenho das máquinas e equipamentos.

Essas características indicam a importância desse tipo de análise econômica na análise da firma do ponto de vista dos seus processos de gestão. Como parte do conhecimento sobre o funcionamento do negócio é tácito e reside nas mentes dos seus empregados e nas rotinas da firma, todas as políticas de armazenamento e recuperação da informação e do conhecimento envolvem a compreensão de como os agentes econômicos selecionam e acumulam os conhecimentos úteis à sua atividade produtiva. Ao mesmo tempo, não é um processo apenas individual, mas, principalmente, social. Os indivíduos têm capacidade de conhecer apenas uma parcela daquilo que é necessário para os negócios da firma, pois eles possuem racionalidade limitada.

Alterações no ambiente afetam o funcionamento das rotinas e sub-rotinas da firma, e sua adaptação à nova situação depende de rotinas de resolução de problemas desenvolvidas internamente ao longo de sua trajetória e relacionadas a procedimentos que lograram êxito no passado.

Essas abordagens introduzem elementos de realidade e de complexidade na análise da firma, diferentemente da tradição da economia neoclássica. A compreensão da sua importância para o desenvolvimento implica em analisá-las como unidades autônomas de decisão, isto é, com o poder de fazer escolhas e definir comportamentos ad hoc frente ao seu ambiente.

As firmas tornam-se organizações idiossincráticas, que enfrentam desafios diferenciados e tomam decisões com base em conhecimentos próprios e modos de agir específicos (FEIJÓ; VALENTE, 2004). Elas desenvolvem suas funções de produção pela combinação de fatores de forma eficiente, geram e acumulam conhecimentos, além de estabelecer laços com outras firmas, e suas interações originam novas estruturas institucionais (KERSTENETZKY, 1995).

Autores da economia, ao escreverem sobre a firma, também influenciaram as disciplinas da administração e a literatura produzida foi classificada, não sem alguma arbitrariedade, em gerencial (managerial) ou comportamental (behavioral).

Elas têm como ponto de partida comum a recusa do princípio da maximização dos lucros como norma absoluta de decisão da firma. Na primeira linha destaca-se Baumol (1959) e, na segunda, o expoente maior é Simon (1957), com seu princípio da racionalidade humana limitada. Ambas destacam aspectos e variáveis que devem ser tomados como relevantes nos processos de decisão em uma 
organização complexa como uma grande empresa, que opera sob incerteza e num mercado imperfeito (FEIJÓ; VALENTE, 2004).

Pode-se observar que o acesso à informação e seu processamento são elementos fundamentais nas teorias da firma apresentadas, assim como as questões relacionadas às suas competências. As disciplinas da administração foram afetadas por essas teorias, mas a popularização da preocupação com a informação e sua importância na sobrevivência das organizações está relacionada com o novo paradigma tecnológico baseado nas tecnologias de informação e comunicação (TIC's).

No final do século $X X$, ocorreu 0 que foi, por muitos autores, denominado de terceira Revolução Industrial, baseada na microeletrônica (FREEMAN; LOUÇÃ, 2001; FREEMAN; SOETE, 1997). O efeito das TIC's sobre as organizações foi bastante intenso nos últimos 30 ou 40 anos do século passado.

Entretanto, foi a partir da década de 1990 que se observou uma mudança no comportamento de executivos e gerentes de empresas, bem como na reflexão de pesquisadores e professores das áreas ligadas principalmente à administração, economia, tecnologia e ciência da informação, dando origem ao que se batizou como gestão do conhecimento.
De acordo com Hansen et al. (1999), a gestão do conhecimento (GC) e as denominações correlatas não são novidade em termos práticos, nem mesmo do ponto de vista do deslocamento do foco da análise do sucesso da empresa, de fatores naturais e tangíveis para os ativos intelectuais, intangíveis em sua grande maioria.

No entanto, segundo os autores, foi a consolidação do paradigma da microeletrônica, a partir de 1990, que estabeleceu as práticas conscientes de GC, fortemente apoiadas nas tecnologias de informação e comunicação (TIC's). Essas tecnologias tornaram possível a codificação, o tratamento, a armazenagem, a recuperação e o compartilhamento da informação de forma mais fácil e barata do que em qualquer período anterior da história (HANSEN et al, 1999).

Conforme apresentado acima, o conhecimento da empresa reside nos indivíduos e nas rotinas estabelecidas. Depreende-se daí que os sistemas de informação e comunicação são apenas parcialmente formais, isto é, baseados em dispositivos, aplicativos e normas formais. Eles possuem uma parcela baseada na comunicação implícita para o desempenho das rotinas e dos indivíduos.

Embora o conhecimento organizacional esteja armazenado nos dispositi- 
vos formais, muitos autores terminam por enfatizar apenas os aspectos ligados ao conhecimento dos membros da organização, o conhecimento tácito, como, por exemplo, Nonaka e Takeushi (1998), que afirmam ser esse o tipo de conhecimento mais importante.

Em geral, os autores mais citados na área de GC (CHOO, 1998; DAVENPORT; PRUSAK, 1998; HANSEN et al., 1999; NONAKA; TAKEUCHI, 1998) defendem a tese de que a gestão do conhecimento está ligada, de forma indissociável, à gestão de pessoas e que o uso das TIC's e das práticas gerenciais é relevante para a criação de um ambiente adequado ao compartilhamento da informação e do conhecimento. Para esses autores, a importância das rotinas e das redes internas como canais de informação e de conhecimento é menor e fica subordinada aos aspectos cognitivos dos indivíduos.

Observa-se essa percepção em autores que estudam o tema no Brasil (CIANCONI, 2003; NEHMY, 2000). Por exemplo, Cianconi (2003) chama a atenção que o termo 'Gestão do Conhecimento', embora seja amplamente empregado, é inadequado e deve ser encarado como uma metáfora, "uma vez que o conhecimento é inerente ao ser humano e não se transfere diretamente" (CIANCONI, 2003, p.16). As técnicas de GC servem para estimular o aprendizado, o compartilhamento e o registro do conhecimento e "uma vez codificado o conhecimento, este se torna informação em potencial, passível, esta sim, de ser gerenciada" (CIANCONI, 2003, p.16).

A GC é uma forma de ir além da mera gestão da "informação formal, registrada, passando ao mundo mais difuso dos ativos intangíveis, aos canais informais de comunicação e ao chamado capital intelectual" (CIANCONI, 2003, p.90). As ações de GC devem facilitar o aprendizado, lidando com os aspectos humanos das organizações e o conhecimento tácito dos indivíduos, o que representa avanço em relação à gestão da informação. A autora constata que a GC é, além de uma metáfora, um guarda-chuva que abriga inúmeras práticas voltadas para a gestão da informação, da comunicação e das tecnologias de informação.

As ferramentas de GC, relativamente pouco utilizadas, são aquelas voltadas para facilitar o contato entre as pessoas e o compartilhamento do conhecimento. "O discernimento e entendimento das duas entidades (informação e conhecimento) é fundamental para os resultados positivos dos programas de Gestão do Conhecimento" (CIANCONI, 2003, p.252 As conclusões da autora confirmam a observação apresentada acima, ou seja, que as discussões sobre GC atribuem 
uma importância maior ao conhecimento tácito em relação ao conhecimento explicitado e demais aspectos da organização, como suas rotinas e outras formas de capital. A introdução do conceito de capital social e, de forma associada, do conceito de redes sociais, que the fornece a infra-estrutura de sustentação, permite ampliar a compreensão das práticas de GC e de sua importância para o desenvolvimento das competências da firma.

\section{A GESTÃO DO CONHECIMENTO E} O CAPITAL SOCIAL: AS REDES E SUA IMPORTÂNCIA PARA AS ORGANIZAÇÕES

Os modelos de Choo (1998) e Nonaka e Takeushi (1998), da mesma forma que o de Dixon (2000), enfatizam a importância dos laços interpessoais para a criação do conhecimento. Todavia, eles não destacam a importância das redes sociais existentes no interior das organizações. A análise de redes sociais (ARS) é uma metodologia usada para se estudar a troca de recursos entre atores, sendo a informação um dos recursos estudados (HAYTHORNTHWAITE, 1996).

A ARS vem sendo aplicada nos ambientes de negócios, uma vez que "as pessoas, em organizações, contam com a sua rede de relacionamento para encontrar informações e resolver proble- mas" (TOMAÉL, 2005, p.103) e que "em um ambiente de rede, criar e compartilhar conhecimento tácito requer a adoção de técnicas de trabalho em colaboração e o estabelecimento de relacionamentos e de confiança entre os atores" (TOMAÉL, 2005, p.107).

Dessa forma, as redes são componentes chaves para o sucesso das práticas de gestão do conhecimento (GC), sendo os elementos constituintes do capital social.

Conforme apresentado anteriormente, dentre os estudos organizacionais que utilizam a ARS, a área que vem revelando maior produção trabalha com o conceito de capital social (BORGATTI; FOSTER, 2003).

Segundo esses autores, nas pesquisas sobre GC observa-se, crescentemente, a aplicação do conceito de capital social para explicar o comportamento informacional dos gerentes, inclusive por autores que analisam o funcionamento das redes internas sem utilizar a metodologia de ARS (BROWN; DUGUID, 2001; DAVENPORT; PRUSAK, 1998). Segundo Tsai e Ghoshal (1998), o uso do conceito de capital social nas empresas se relaciona à existência de re-

\footnotetext{
${ }^{3}$ A ciência da informação se ocupa, há bastante tempo, de diversos aspectos das estruturas sociais de conhecimento sem usar o conceito de capital social (WIDÉN-WULFF; GINMAN, 2004, p. 456).
} 
cursos incrustados nos relacionamentos pessoais que podem ser usados em proveito dos indivíduos e das organizações. Esses autores estudaram como o capital social contribui para a criação de valor na firma, na forma de inovações. Para tal, eles identificaram três dimensões do capital social: estrutural, relacional e cognitiva (também denominada de dimensão de conteúdo ou de comunicação).

O capital estrutural permite que 0 indivíduo obtenha vantagens, pois inclui a interação social e a posição do ator na rede e seus contatos permitem que ele obtenha informações vantajosas (vantagem no acesso a recursos). Já o capital relacional se refere a ativos que estão residentes nas relações, como a confiança.

Por fim, a dimensão cognitiva se relaciona com o compartilhamento de códigos, modelos e paradigmas que facilitam a compreensão dos objetivos da coletividade e das normas para atuar naquela sociedade. Essa compreensão comum é apropriada pela coletividade como um recurso (TSAl; GHOSHAL, 1998).

Em sua pesquisa, Tsai e Ghoshal (1998) analisam a relação entre unidades de negócios de uma empresa, destacando como as três dimensões interagem entre si, como influenciam a combinação e troca de recursos entre as unidades e como esses processos influenciam a cri- ação de valor no desenvolvimento de novos produtos, ou seja, na inovação.

As três dimensões do capital social de Tsai e Ghosal podem ser aproximadas da união dos conceitos de conhecimento cultural (CHOO, 1998) e de ambiente de criação de conhecimento (NONAKA; KONNO, 1998). Cabe também destacar que os laços estudados são interpessoais, mas, também, interdepartamentais, e as relações entre essas entidades (pessoas e departamentos) na criação do conhecimento são identificadas com a dimensão ontológica da criação do conhecimento no modelo de Nonaka e Takeushi (1998).

Os resultados obtidos confirmam 0 argumento de que o capital social facilita a criação de valor nas organizações, e estão de acordo, segundo Tsai e Ghoshal (1998), com outras pesquisas que evidenciam que as organizações podem obter vantagens do compartilhamento de recursos entre as suas unidades de negócio.

A análise sugere, ainda, que 0 investimento em capital social dentro das organizações ajuda na criação de valor. Os investimentos em técnicas de gestão e infra-estrutura têm retorno, pois as relações sociais informais e os acordos tácitos encorajam a troca e a combinação de recursos. Porém, como as unidades de negócios possuem diferentes recursos 
e são, de fato, seus detentores, ampliar o alcance e o escopo dos laços entre os departamentos seria mais significativo para os resultados das organizações, do que aumentar os laços interpessoais (TSAI; GHOSHAL, 1998).

Anklan (2002) analisa a importância da GC para o compartilhamento do conhecimento tácito e o uso de tecnologias para facilitar o ambiente de redes e o desenvolvimento do capital social. Ele associou o desenvolvimento da GC à ampliação da aplicação das tecnologias de informação e comunicação (TIC's) na gestão dos recursos informacionais das empresas.

O uso das TIC's amplia, exponencialmente, o acesso ao conhecimento explícito armazenado, que pode ser representado, quando necessário, por alguns 'artefatos': relatórios, estudos de caso, projetos e planos, metodologias, informações dos clientes, dentre outros. Os artefatos são os elementos-chave do lado 'real' da GC em uma empresa e as tecnologias de acesso e manipulação desses artefatos (TIC's) representam uma parte essencial do processo (ANKLAN, 2002).

As TIC's permitem, também, a superação parcial das barreiras à comunicação entre as pessoas, com o desenvolvimento de ferramentas de suporte (páginas amarelas, divulgação das meIhores práticas, intranets, etc.). As raízes dessas ferramentas são as tecnologias de suporte para a integração de grupos (groupware e group decision technologies) que permitem a criação e ampliação das comunidades de prática, de aprendizado, de interesses e de objetivos (ANKLAN, 2002).

Anklan (2002) define o capital social como o "estoque de relações, contexto, confiança e normas que permitem 0 comportamento adequado para o compartilhamento do conhecimento" (ANKLAN, 2002, p.9-10, tradução nossa). Em conjunto com outras formas nãotangíveis de capital (estrutural, dos clientes) e o capital humano, formam o capital intelectual da organização (fig. 2). 


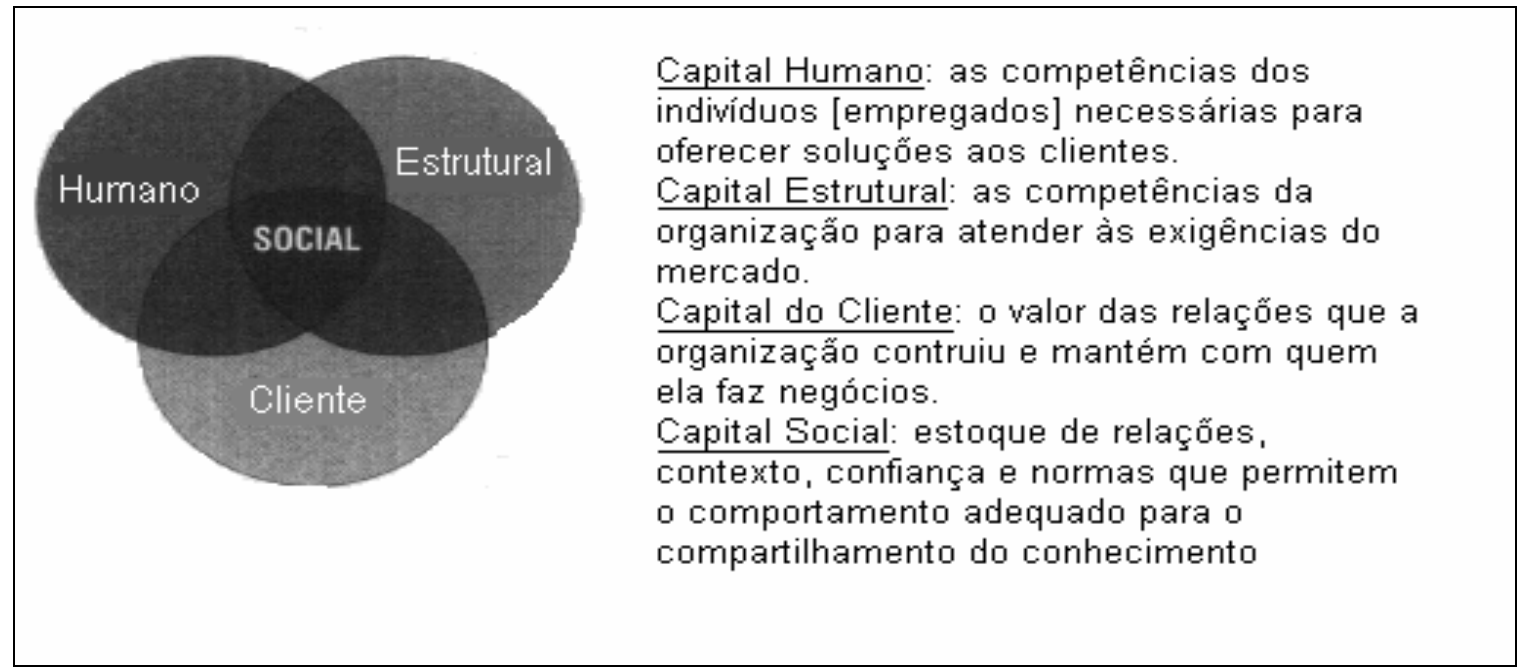

Figura 2 - Componentes do Capital Intelectual. Fonte: Adaptado de Anklan (2002).

Segundo Widén-Wulff e Ginman (2004), poucas pesquisas relacionam o comportamento informacional e o capital social, embora outras, que ligam os aspectos sociais dos indivíduos aos seus comportamentos informacionais, sejam frequentes. A maioria das pesquisas, portanto, se preocupa com o comportamento do indivíduo, com pouca ênfase nas dimensões sociais que afetam o comportamento informacional e o compartilhamento do conhecimento.

Segundo Widén-Wulff e Ginman (2004), essa preocupação surge como um desafio para a GC, que pode ser decomposto em quatro dimensões: 1) técnica, na qual: as TIC's inspiram a visão de uma gestão efetiva da informação e do conhecimento, mas não garantem que a visão se transforme em ação; 2) gerencial, na qual a necessidade de se realizar ações para que um ambiente adequado ao compartilhamento do conhecimento seja criado; 3) individual, que se relaciona com a abertura a novas idéias, que se relaciona com o fato do conhecimento tácito residir na mente dos empregados e deve ser gerenciado com o uso de uma abordagem cognitiva; 4) social, que implica no desenvolvimento de uma comunidade que compartilhe o conhecimento. Os indivíduos têm parte de sua força extraída de suas redes, de acordo com o paradigma do capital social.

As dimensões de números 2 e 3 se relacionam com a cultura informacional da organização, enquanto a de número 4 representa o maior desafio para a GC. ${ }^{4}$

Segundo Widén-Wulff e Ginman (2004), o comportamento informacional nas redes sociais pode ser associado ao traba-

${ }^{4}$ De acordo com Widén-Wulff e Ginman (2004, p. 449), o desafio está posto para a ciência da informação $(\mathrm{Cl})$, isto é, deve-se buscar entender como o compartilhamento do conhecimento se relaciona com o capital social. 
Iho de Choo (1998), mesmo que esse autor não utilize esse conceito. $O$ capital humano é a base do conhecimento dos indivíduos, mas o conhecimento necessita de uma dimensão social para ser compartilhado.

Para Widén-Wulff e Ginman (2004), as empresas são capazes de mapear desafios e oportunidades e os processos de decisão são baseados na responsabilidade coletiva e na perspectiva global, definidas pelos altos executivos e compartilhadas por seus integrantes: "O compartilhamento do conhecimento é uma atividade com múltiplas dimensões e engloba habilidades cognitivas e de comunicação em um determinado contexto" (WIDÉN-WULFF; GINMAN, 2004, p.453, tradução nossa). Para o sucesso das empresas, o seu processo de comunicação deve se tornar uma competência fundamental (TEECE, 2005).

Segundo Widén-Wulff e Ginman, observa-se certa 'frouxidão' (no sentido de pouca tensão ou pouca rigidez) organizacional nas empresas que compartilham conhecimento, resultado que vai ao encontro do conceito de capital social apresentado por Burt $(2000,2001)$.

Com relação à dimensão técnica, é preciso observar que grupos distintos demandam diferentes plataformas de TIC's. Estas devem se adequar às necessidades dos indivíduos, não perdendo de vista que eles compartilham, em suas comunidades, uma história, experiências e uma lingua- gem que permitem a comunicação de sua realidade (WIDÉN-WULFF; GINMAN, 2004). O papel da tecnologia como suporte à gestão do capital social é, também, tratado por Huysman e Wulf (2006) e por Davenport e Snyder (2005). Ambos os trabaIhos destacam o papel das TIC's como ferramentas de suporte ao compartilhamento do conhecimento nas organizações, que permitem que seu capital social se torne visível de uma forma que não era possível antes de sua existência.

As TIC's afetam os processos de coordenação e integração, pois atingem, inclusive, os limites da firma. Essas tecnologias afetam os custos de transação e as práticas de externalização do conhecimento, mudando as configurações das redes internas (de indivíduos e outras estruturas, como departamentos) e externas (entre organizações) (FORSAY, 2000; WILLIAMSON, 1995). Em outras palavras, as TIC's afetam o valor do capital social.

Citando pesquisas na área, Bender (2004) aponta que as TIC's afetam tanto as transações internas quantos as externas às firmas. Os estudos mostram que, inicialmente, os impactos foram maiores nas transações internas, com a introdução de aplicativos de gestão de recursos das empresas (enterprise resource planning (ERP) software). Porém, em seguida, novas formas e recursos de TIC's (como a Internet e sistemas de informação interorganizacio- 
nais ou interorganizational information systems) levaram a um maior relacionamento interorganizacional e permitiram maiores ganhos de produtividade nas relações mercantis entre diferentes empresas.

Ou seja, essas tecnologias reduziram, inicialmente, os custos internos de transação, para, em seguida, reduzir os custos externos. Estes últimos também têm impacto na estrutura das empresas, pois as TIC's permitem uma melhor gestão da escolha entre produzir internamente ou comprar fora, diminuindo os custos de transação, fixos e variáveis, referentes à coordenação das atividades econômicas.

Em sua conclusão, baseada em ampla pesquisa empírica, Bender (2004) confirma que as fronteiras das firmas foram afetadas pela difusão dessas tecnologias, em direção a empresas menores e mais voltadas para o seu negócio principal (core capabilitie), pois as TIC's possibilitam o aumento coordenado do número de parceiros pelo seu amplo potencial de controle de informações e processos.

Como conseqüência, os limites entre firma e mercado passam a levar em conta modos de relação cooperativos intermediários. As redes são um novo tipo de organização que surge como resposta à crescente incerteza, ao aumento do risco e do custo de processamento de informações. As empresas procuram relações mais colaborativas, envolvendo cooperação e confian- ça, e as TIC's ampliam os limites das redes de empresas (FEIJÓ; VALENTE, 2004). Assim, as técnicas de GC têm que ser adaptadas a um ambiente mais amplo, que envolva toda a cadeia produtiva e as organizações de apoio ao negócio.

\section{CONCLUSÃO}

O artigo apresenta, de forma sucinta, o conceito de redes sociais e sua importância para a compreensão do capital social. Seu objetivo é destacar a importância dessa forma de capital para os processos de criação de conhecimento nas firmas. No entanto, a firma é um conceito que não é regularmente discutido nem na literatura de Gestão do Conhecimento, nem na literatura de Ciência da Informação.

Assim, fez-se uma breve apresentação da teoria da firma, conforme as principais correntes da ciência econômica. Destacou-se a crítica à visão neoclássica da firma e a incorporação de elementos mais próximos à realidade, como os conceitos de custos de transação, que se relacionam, dentre outros aspectos, com os custos associados à busca e ao processamento da informação, com a racionalidade limitada dos indivíduos, com a necessidade de trabalho em equipe e com o papel das rotinas e do conhecimento tácito na constituição das competências das firmas. Esses aspectos tratados pela teoria econômica trouxeram mudanças na forma como as 
disciplinas de administração entendem o ambiente interno das organizações. Essas mudanças foram reforçadas pela incorporação, em grande escala, das TIC's aos processos administrativos.

O resultado mais profícuo dessas mudanças foi o reconhecimento do papel relevante das TIC's nos processos de criação de conhecimento no interior das empresas e de introdução de inovações, sem perder de vista a relevância do capital humano e a importância do conhecimento tácito, subordinadas ao contexto da organização e às suas rotinas de funcionamento.

Da mesma forma que as TIC's facilitam o funcionamento das redes internas às empresas, elas abrem possibilidades de ampliação do espaço de cooperação existente entre diferentes empresas.

As relações interpessoais nas empresas criam redes sociais que permitem trocas de recursos informacionais, que criam valor para as empresas se ocorrem em um ambiente que valorize a cooperação e a confiança. As redes e as características do ambiente são componentes do capital social das organizações, sendo as primeiras fundamentais para a compreensão do acesso a grande parte das informações, além de fornecerem sustentação aos mecanismos de conversão do conhecimento. Aceitas essas relações, a GC pode ter seu alcance ampliado, englobando, também, a gestão do capital social.

\section{REFERÊNCIAS}

ALLEN, Thomas J. Managing the flow of technology. Cambridge: MIT Press, 1985.

ANKLAN, Patti. Knowledge management: the collaboration thread. Bulletin of the American Society for Information Science and Technology. Silver Spring, v.28, n.6, p.8-11, Aug./Sept. 2002.

BAUMOL, William Jack. Business behavior, value and growth. New York: Macmillan, 1959. 164p.

BENDER, Christian. The Theory of the Firm Revisited: changing firm boundaries in a new information and communication environment. In.: WORKSHOP ON

INSTITUTIONAL ANALYSIS AT THE UNIVERSITAT POMPEU FABRA, 3. 2004.

Proceedings... Barcelona: Universitat Pompeu Fabra, 2004. Disponível em: $<$ http://www.isnie.org/ISNIE02/Papers02/be nder.pdf>. Acesso em: 06 jul. 2004.

BORGATTI, S.P.; CROOS, R. A relational view of information seeking and learning in social networks. Management science. Evanston, v.49, n.4, p.432-445, Apr.2003.

BORGATTI, S.P.; FOSTER, P.C. The network paradigm in organizational research: a review and typology. Journal of management. Stillwater, v.29, n.6, p.991-1013, 2003.

BOURDIEU, Pierre. The forms of capital. In: RICHARDSON, J. (Comp.). Handbook of theory and research for the sociology of education. New York: Greenwood, 1985.

BROWN, John Seely; DUGUID, Paul. A vida social da informação. São Paulo: Makron Books, 2001. 284 p.

BURT, R.S. Structural holes versus network closure as social capital. In LIN, Nan; COOK, Karen; BURT, Ronald (Ed.). Social Capital: theory and research. New York: Aldine de Gruyter, 2001. 
BURT, R.S. Structural holes: the social structure of competition. Cambridge: Harvard University Press, 1995.

BURT, R.S. The network structure of social capital. In.: SUTTON, Robert I.; STAW, Barry M. (Ed.). Research in organizational behavior. Greenwich: Jai Press, 2000.

BURT, R.S.; HOGARTH, R.M.; MICHAUD, C. The social capital of french and american managers. Organization science, Providence, v.11, n.2, p.123-147, 2000.

CARLEIAL, Liana. Redes industriais de subcontratação: um enfoque de sistema nacional de inovação, um estudo das industrias eletrônica, metalmecânica e de confecções da Região Metropolitana de Curitiba. São Paulo: Hucitec, 2001. 210 p.

$\mathrm{CHOO}$, Chun Wei. The knowing organization: how organizations use information to construct meaning, create knowledge, and make decisions. New York: Oxford University Press, 1998. 298 p.

CIANCONI, Regina de Barros. Gestão do conhecimento: Visão de indivíduos e organizações no Brasil. 2003. 287f. Tese (Doutorado em Ciência da Informação) - Instituto Brasileiro de Informação em Ciência e Tecnologia/Universidade Federal do Rio de Janeiro, Rio de Janeiro, 2003.

COASE, R.H. (1937). The nature of the firm, Economica, London, v.4, p.386-405, 1937.

COLEMAN, James S. Foundantions of social theory. Cambridge: Harvard University Press, 1990. p.993.

COLEMAN, James S. Social capital in the creation of human capital. American journal of sociology. Chicago, v. 94, p. 95-120, 1988.

DAVENPORT,T.H.; PRUSAK, L. Conhecimento empresarial: como as organizações gerenciam o seu capital intelectual. Rio de Janeiro: Campus, 1998.
DAVENPORT, Elizabeth; SNYDER, H.W. Managing Social Capital. Annual Review of Information Science and Technology, New York, v.39, p.517-550, 2005.

DEGENNE, Alain; FORSÉ, Michel. Les réseaux sociaux: une analyse structurale en sociologie. Paris: Armand Colin, 1994.

DIXON, Nancy M. Common knowledge: how companies thrive by sharing what they know. Cambridge: Harvard Business Press, 2000.

DURSTON, John. El capital social campesino en la gestión del desarrollo rural: Díadas, equipos, puentes y escaleras. Santiago de Chile: Comisión Económica para América Latina y el Caribe (CEPAL), 2002.

FEIJÓ, Carmem Aparecida; VALENTE, Élvio. A firma na teoria econômica e como unidade de investigação estatística: evolução nas conceituações. Revista de Economia Contemporânea, Rio de Janeiro, v.8, n.2, p.351-376, jul.2004.

FORSAY, Dominique. L'economie de la connaisance. Paris: Éditions La Découverte, 2000.

FREEMAN ${ }_{2}$ C. Networks of innovators: a synthesis of research Issues. Research Policy, Amsterdam, n.20, 1991, p.499-514.

FREEMAN, C.; LOUÇÃ, F. As time goes $b y$ : from the industrial revolution to the information revolution. Oxford: The Oxford University Press, 2001. 407 p.

FREEMAN, C.; SOETE, L. The economics of industrial innovation. 3.ed. Cambridge: MIT Press, $1997.470 \mathrm{p}$.

GLAESER, Edward; LAIBSON, David ; SACERDOTE, Bruce. An economic approach to social capital. Economic journal. Oxford, v. 112, n. 483, p 437-458, nov. 2002.

GRANOVETTER, Mark. Business Groups. In: SMELSER, Neil J.; SWEDBERG, Richard $(\mathrm{Ed})$. The handbook of economic soci- 
ology. New Jersey: Princeton University

Press, 1994, $835 \mathrm{p}$.

GRANOVETTER, Mark. The strength of weak ties. American Journal of Sociology, Chicago, v.78, n.6, p.1360-1380. May 1973.

GROSSER, Kerry. Human networks in organizational information processing. Annual Review of Information Science and Technology, New York, v.26, p.349-402, 1991.

HANSEN, Morten et al. What's your strategy for managing knowledge. Harvard Business Review, Boston, Mar./Apr.1999.

HAYTHORNTHWAITE, Caroline. Social network analysis: an approach and technique for the study of information exchange. Library and Information Science Research. , v. 18, p.323-342, 1996.

HUYSMAN, Marleen; WULF, Volker. It to support knowledge sharing in communities, towards a social capital analysis. Journal of Information Technology, London, v.1, n.21, p.40-51, Feb. 2006.

KERSTENETZKY, Jaques. Firmas e Mercados: uma análise histórico-instituciuonal do problema da coordenação. 1995. Tese (Doutorado em Economia) - Departamento de Economia, Universidade Federal do Rio de Janeiro, Rio de Janeiro, 1995.

KRACKHARDT, David. Cognitive Social Structures. Social Networks, Amsterdam, v.9, p.109-134, 1987.

KRACKHARDT, David; HANSON, Jeffrey R. Informal networks: the company behind the chart. Harvard Business Review, Boston, p.104-111, Jul./Aug.1993.

LIN, Nan et al. The position generator: measurement techniques for investigations of social capital. In.: LIN, Nan; COOK, Karen; BURT, Ronald (Eds). Social Capital: theory and research. New York: Aldine de Gruyter, 2001.
MACÍAS, Alejandro García. Redes sociales y "clusters" empresariales. Revista Hispana para el Análisis de Redes Sociais, Barcelona, v.1, n.6, Jan.2002. Disponível em: $<$ http://revista-redes.rediris.es $/ \mathrm{html}$ vol1/vol1 6.htm>. Acesso em: 15 jul. 2004.

MARTELETO, Regina Maria. Análise das redes sociais: aplicação nos estudos de transferência da Informação. Ciência da Informação, Brasília, v.30, n.1, p.71-81, jan./abr. 2001.

MINTZBERG, Henry. The structuring of organizations: a synthesis of the research. Prentice-hall, 1979. $512 \mathrm{p}$.

MOLINA, José Luis. The informal organizational chart in organizations: An approach from the social network analysis. Connections, Los Gatos, v.24, n.1, p.78-91, 2000.

NEHMY, Rosa Maria Quadros. O ideal do conhecimento codificado na era da informação: o programa de gestão do conhecimento. 2000. Tese (Doutorado em Ciência da Informação) - Escola de Ciência da Informação, Universidade Federal de Minas Gerais, Belo Horizonte, 2000.

NELSON, Richard R; WINTER, Sidney G; Economic change: an evolutionary theory of economic change. Cambridge: Belknap Pr, 1982. 437p.,1v.

NONAKA, I.; KONNO, N.; The concept of 'Ba': Building a foundation for knowledge creation. California Management Review, Berkeley, v.40, n.3, 1998.

NONAKA, I.; TAKEUCHI, H. Criação de conhecimento na empresa: como as empresas japonesas geram a dinâmica da inovação. Rio de Janeiro: Campus, 1998.

PAVITT, Keith. Can the large penrosian firm copo with the dynamics of technology? Science and Technology Policy Research, Sussex, n.68, Sep.2001.

PENROSE, Edith T. The theory of the growth of the firm. Oxford: Blackwell, 1959. 
PUTNAM, Robert D. Comunidade e democracia: a experiência da Itália moderna. Rio de Janeiro: FGV, 1996, 257p.

RICHARDSON, G.B. The Organization of Industry. The Economic Journal. London, v.82, p.883-896, 1972.

ROCHA, Cristóbal Casanueva. Relaciones estratégicas entre pymes: contraste de hipótesis empresariales mediante ARS. Revista Hispana para el Análisis de Redes Sociais, Barcelona, v.4, n.4, jun.2003.

SAXENIAN, Annalee. Regional Advantage: culture and competition in Silicon Valley and Route 128. Cambridge: Harvard University Press, 1996.

SILVA, Antonio Braz de Oliveira e. O cluster da construção em Minas Gerais e as práticas de colaboração e de gestão do conhecimento: um estudo das empresas da Região Metropolitana de Belo Horizonte (MG). 2007. Tese (Doutorado). Esola de Ciência da Informação, Universidade Federal de Minas Gerais, Belo Horizonte, 2007.

SIMON, Herbert Alexander. Administrative behavior: a study of decision-making processes in administrative organization. 2.ed. New York: Free Press, 1957. 259p.

TEECE, David J. As aptidões das empresas e o desenvolvimento econômico: implicações para as economias de industrialização recente. In: KIM, Linsu; NELSON, Richard R. Tecnologia, aprendizado e inovação: a experiência das economias de industrialização recente . Campinas: Unicamp, 2005. p.147-178.

TOMAÉL, Maria Inês. Rede de Conhecimento: o compartilhamento da informação e do conhecimento em consórcio de exportação do setor moveleiro. 2005. 292 f. Tese (Doutorado) - Escola de Ciência da Informação, Universidade Federal de Minas Gerais, Belo Horizonte, 2005.

TSAI, Wenpin; GHOSHAL, Sumatra. Social capital and value creation: the role of in- trafirm networks. Academy of Management Journal, Champaign, p.464-476, Aug.1998.

WASSERMAN, Stanley; FAUST, Katherine. Social Network Analysis: methods and applications. In: Structural analysis in social the social sciences series. Cambridge: Cambridge University Press, 1999. v.8. 857p.

WATTS, Duncan J. Small worlds: the dynamics of networks between order and randonmness. Princeton University Press, 1999.

WIDÉN-WULFF, Gunilla; GINMAN, Mariam. Explaining knowledge sharing in organizations through the dimensions of social capital. Journal of Information Science. London, v.5, n.30, p.448-458, 2004.

WILLIAMSON, Oliver E. Transaction cost economics and organization theory. In: WILLIANSOM, Oliver E. (Comp.). Organization Theory: from Chester Barnard to the present and beyond. New York Oxford: Oxford University Press, 1995. Cap.9, p.207256.

Antonio Braz de Oliveira e Silva

Doutor em Ciência da Informação (UFMG), Analista do IBGE-MG; Fundador do Netic Núcleo de Estudos em Tecnologias para Informação e Conhecimento antonio_braz@uol.com.br

\section{Marta Araújo Tavares Ferreira}

Doutora em Engenharia Industrial e Gestão da Inovação Tecnológica (École Centrale de Paris), Professora Associada da UFMG, Professora do Centro Universitário UNA /MG maraujo@ufmg.br 


\section{Title}

Knowledge management and social capital: networks and their relevance for enterprises

\begin{abstract}
This article outlines the main aspects of the concept of social capital, its relation with the social networks and its relevance for the creation of knowledge inside enterprises. Social Network Analysis (SNA) investigates the links between social actors, which can be people, departments of a firm or enterprises in a region. The links between them can be, for example, friendship, information on production or supply of goods. Behavior of the individuals inside the firms is supposed to depend-on the social relations and the existing routines. The action of the firms also depends on their suppliers and consumers networks. Both are part of the firms' social capital. It can be observed the increasing literature describing the use of SNA in the research about information flow and knowledge creation inside the firms. Nevertheless, researches in knowledge management rarely make use of the concept of social capital. The use of SNA in those researches would improve the quality of their findings.
\end{abstract}

Key words: social capital, social networks, knowledge management, theory of the firm

\section{Título}

Gerencia del conocimiento y capital social: redes y su importancia para las empresas

\section{Resumen}

Este artículo destaca los aspectos principales del concepto del capital social, su relación con las redes sociales y de su importancia para la creación del conocimiento en las empresas. El análisis de redes sociales (ARS) investiga los lazos presentes entre los actores sociales, que pueden ser personas, departamentos de una firma o empresas en una región. Los lazos entre ellos pueden ser, por ejemplo, amistad, información sobre la producción o la provisión de mercancías, respectivamente. Se supone que, dentro de las firmas, el comportamiento de los individuos depende de las relaciones sociales y de las rutinas existentes. La acción de las firmas también depende de sus redes de suplidores y de consumidores. Ambas las redes son parte del capital social de las empresas. Observa-se el incremento en la literatura que describe el uso de la ARS en la investigación sobre el flujo de la información o la creación del conocimiento dentro de las firmas. Sin embargo, en lo tocante a la gerencia del conocimiento, las investigaciones poco frecuentemente hacen uso del concepto de capital social. El uso de la ARS en esas pesquisas mejoraría la calidad de sus resultados.

\section{Palabras claves}

Capital social, redes sociales, gerencia del conocimiento, teoría de la firma 